\title{
Voor-woord / voor-beeld
}

"Docenten lazen kennelijk vrijwel nooit de docentenhandleiding", zegt Siel van der Ree in een interview in dit nummer. Waarschijnlijk geldt iets soortgelijks als het gaat om "voorwoorden" in boeken of tijdschriften. Je bladert snel door. Kijkt naar de plaatjes. Je ogen scannen een paar interessante trefwoorden. Een woord, een beeld, en plotseling word je in het verhaal getrokken. Om er aan het eind misschien zelfs betrokken uit te komen. Misschien zou een voor-beeld beter zijn dan een voor-woord?

We leven in een visuele cultuur - of woorden (!) van gelijke strekking horen we vaak zeggen. We denken: woorden verliezen hun kracht. Woorden worden werkeloos. Immers, een plaatje zegt meer dan duizend woorden, toch? En woorden op papier lijken nog krachtelozer te worden dan het levende, gesproken woord. In hetzelfde interview zegt Van der Ree: "Bij de hoofdvakstudie geconfronteerd met studenten uit een totaal andere leefwereld, die hoegenaamd niets gelezen hadden, qua studievaardigheid het veel meer van het beeld en het gespróken woord dan van teksten moesten hebben (ze zouden nu massaal You Tube raadplegen) en die aangesproken wilden worden in hùn denkcategorieën, heb ik gedwongen afstand leren nemen van traditionele termen en begrippen in de taalkunde."

Toch zijn er tussen beelden en woorden krachtige banden. Metaforen dragen beelden in woord-vorm, zelfs al herkennen we die beelden soms niet meer. Beelden uit het verleden zijn soms alleen nog maar te begrijpen door middel van een uitleg met woorden. Woorden vullen beelden aan, en omgekeerd. Bovendien roepen beelden, als ze indruk op ons maken, 
vrijwel automatisch een reactie in woorden op: Wat mooi! Wat verschrikkelijk! Wat lief! Beelden verbonden met woorden: daar gaat dit themanummer van Acta Neerlandica over.

Ferenc Postma verdiepte zich - niet geheel onverwacht - in zeldzaam $17^{\text {de }}$ eeuws academisch drukwerk uit Franeker dat terechtkwam in de Klimo bibliotheek in Pécs. Zijn artikel geeft ons een beter beeld van het leven van István S. Mányoki, tijdens zijn studie aan protestantse universiteiten in Groningen, Franeker, Leiden en Utrecht tussen 1646-1648.

De studie van Maarten Aalders verschaft een beeldende levensbeschrijving van ds. Han Munnik (1884-1969), die zich inzette om studiebeurzen te organiseren voor Hongaarse theologiestudenten.

Maja Szücs geeft een boeiende inkijk in het veelbewogen leven van een bijna vergeten filmmaker, George Pal (1908-1980), die een belangrijke rol speelde bij de totstandkoming van animatiefilms.

Róbert Kerepeszki laat in beeld en woord zien hoe in oude bioscoopjournaals de problemen van studenten in de chaotische omstandigheden na de Eerste Wereldoorlog weergegeven worden.

Het artikel van Gábor Pusztai gidst ons langs wat nog is overgebleven van ooit op Sumatra tentoongestelde aquarellen die geschilderd zijn door László Székely. Door de ogen van de kunstenaar krijgen we portretten te zien van 'alledaagse' mensen in het Nederlands-Indië in de twintiger jaren van de twintigste eeuw.

Kees Teszelszky laat vervolgens zien hoe de gedetailleerde zoekfuncties van Delpher, de gedigitaliseerde collectie van historische Nederlandse kranten en tijdschriften, te gebruiken zijn om soms ook onverwachte Hongaars-Nederlandse contacten in beeld te krijgen. Zijn artikel delft diep in Delpher en diept daaruit in woord en beeld de geschiedenis op van een Hongaarse familie in Den Haag vlak voor en tijdens de Tweede Wereldoorlog. Tot aan het eind van het artikel blijft het een verrassing om welke familie het hier gaat.

Albert Gielen gaat in zijn bijdrage in op de vraag wat geldt als plagiaat in de postmoderne beeldende kunst en hoe het denken daarover vorm krijgt in Joost Zwagermans roman Gimmick!

Margriet Gosker geeft ons een blik in haar verzameling van afbeeldingen van de bijbelse gelijkenis over de "Verloren zoon". Het is uiterst interessant om te ontdekken op welke aspecten van dit bekende verhaal kunstenaars in hun werk de nadruk hebben gelegd. In het artikel zien we niet alleen afbeeldingen, maar horen ook knorrende magen naast knorrende beesten. 
Željana Pancirov Cornelisse, Ana Marija Žagar en Frieda Steurs hebben onderzoek gedaan naar hoe een combinatie van beeld en tekst mensen kan beïnvloeden en hoe auteurs een tekst overtuigend kunnen maken. Ze doen dat aan de hand van positieve en negatieve lezerservaringen van een toeristenbrochure van Zagreb, de hoofdstad van Kroatië. Een waardevol voorbeeld van feedback door verschillende lezersdoelgroepen, dat ook op andere teksten toegepast zou kunnen worden.

In deze Acta Neerlandica vinden we ook weer een aantal voortreffelijke interviews met Nederlandstalige gesprekspartners die op verschillende manieren een band hebben met Hongarije en het Hongaarse taalgebied. Een ontmoeting met concrete mensen levert meestal verrassende verhalen op; dat is ook in deze interviews gelukt. We krijgen een inkijkje in het leven en werk van Kees Teszelszky. Zijn onderzoek rond de Hongaarse kroon en zijn werk bij de Koninklijke Bibliotheek krijgen de aandacht. We blijven nog bij de Koninklijke Bibliotheek in het interview met Melinda Kónya en haar werk als collectiespecialist klassieke en moderne talen en coördinator schenkingen van de KB. In het interview met Mari Alföldy komt het werk van een vertaler van Hongaarse literatuur in het Nederlands voor het voetlicht. En tenslotte zwerven we in het interview met Siel van der Ree tussen Nederland, Hongarije, Nederlands-Indië en Indonesië.

Dit nummer van Acta Neerlandica sluit af met de gebruikelijke mededelingen en boekbesprekingen.

Tot zover dit voor-woord zonder voor-beeld. Waarschijnlijk ongelezen. Blader maar snel door! Misschien zijn er woorden en beelden in dit nummer die je als lezer meenemen in hun verhaal. En worden nieuwe beelden en woorden een deel van je eigen verhaal. 